Reviews

\title{
On China's Villages, Rural industries and Technology Development: A Review Essay with Special Reference to Technology Development in Rural Industries. A Study of China's Collectives[1]
}

\author{
By Dipak R. Pant, Professor of Anthropology, Universita' Carlo Cattaneo, \\ Castellanza, Italy
}

\author{
A Nation of Villages and Townships \\ The majority of Chinese population lives in the villages (cunzhuang) and rural townships
} (xiang) in the vast and relatively underdeveloped interior. Most of the low-paid (and, sometimes, unauthorized) workers criss-crossing the construction sites in urban peripheries have village origins. The sheer size of the rural population (about $70 \%$ of more than 1.2 billion people) makes China essentially a nation of villages, despite the popular representation of high rise buildings, asphalt roads, neon signposts and busy and booming urbanity (mostly along China's coastline) of the last two decades. The real China, the rural interior inhabited by almost 900 million people, has been lagging behind the coastal areas since the colonial 18th century. The gap has even further widened between China's urban (and newly urbanized) areas and its rural interior with the establishment of "Special Economic Zones" (SEZ) following Deng Xiao-ping's reforms (late 1970s - 80s) and the urban concentration of facilities and infrastructural development.

With China's urban economy showing signs of gloom after two decades of sustained growth, hopes are now being pinned on the vast rural hinterland as the next source of growth. Although the rural income has increased significantly since early 1980s, the urban-rural divide in income is still wide. An average Chinese villager earns between one-third to two-fifth of an average citydweller's income (Starr 1997; State Statistical Bureau of the People's Republic of China, 1999). So it is widely held that an increase in rural incomes could have a strong, positive effect on overall consumption, enough to recharge China's increasingly sluggish economy. Once again the villages of China are in the limelight.

Unlike the rural backyards of Europe, of the Americas and of many developing countries, China's villages have always played a primary and special role in the nation's history. The original birthplace of the Han-Chinese civilization is in the interior, in the middle and lower reaches of Hunag He (Yellow) river basin. The architectural and artistic heritage in the interior witnesses the past grandeur and glory of China - that is, what remains after the systematic devastation during the "Great Proletariat Cultural Revolution," from the late 1960s through the early 1970s.

To some extent, the interior has been the test-bed of both communist revolution and the postcommunist liberal reforms. Mao organized his revolutionary campaign, long marches and military actions from the rural interior and, eventually, defeated the urban-based nationalist (Kuomintang) forces in 1949. The agrarian liberalization of Sichuan (the largest interior province, and Hannah Piek's research field) in the late 1970s preceded general economic liberalization of China in the early 1980s. Sichuan's leader, Zhao Ziyang, rose to the central power (to the position of General Secretary of the Communist Party of China) due to his nationwide reputation as successful pioneer in rural agricultural economic reform known as the "household-responsibility system" (since 1989 he has fallen from grace for his sympathy to the demonstrators of the Tien-an-men Square, Beijing).

The rural interior supplies raw materials, food items and cheap labour to the urban areas and to the coastal regions. The rural-urban divide in income, benefits, facilities and opportunities remains wide. The restrictions in changing the residency remain in force. But, unlike earlier 


\section{Reviews}

circumstances, information urban-rural differences is now widely available among the villagers about through mass media, migrations (both seasonal/occasional and long-term) and increased mobility of the rural middle class with modest disposable income that supports travels and so on. In the last five years, the media reports about rural public protests (against taxes, corruption, price rise, for example) and tensions between the local and central authorities have continued to multiply. Apparently, the rural interior of China is silently developing as the breeding ground of popular discontent. The renewed high-level political attention to the rural areas is appropriately viewed as a direct response to a quiet but growing undercurrent.

China's villages are drawing attention from the national policy-makers and international observers for the economic potential as well as for their political significance. The social and political implications of the urban-rural divide and the related economic policy imperatives are only briefly touched upon in Piek's volume, which has as its central focus a detailed case study of the rural industrial economy and technology. As with many case studies, Piek's current work reflects a specialized concern and narrowly constructed focus, perhaps at the expense of omitting key contextual observations of a more organic and encompassing nature.

Bringing industry to the Chinese countryside:

Industrialization - of the "modern Western type" - did not reach China's rural hinterland until the second half of the 20th century. It remains far below the level of industrialization witnessed in the West. Piek's historical notes on merchants, craft businesses and light industries in the Chinese countryside in the past centuries mentions the proto-industrialization of China and the failure to become properly industrialized (in the modern-Western sense) in the 19th and early 20th centuries. But Piek tends to attribute this mainly to the absence of a strong centralized government in the past (i.e., before the People's Republic) that would deliberately pursue a strategy of economic and technological development. I believe this interpretation is unusually simplified, overlooking many factors related to the Chinese habitat, history and culture.

It should not be forgotten that for centuries the vastness of the agro-pastoral land continued to provide resources and space for an expanding Chinese population. With all this land, there were few sustained periods of serious pressure for intensification, concentration in a more limited space, or a quantum leap in economic output. It would be more accurate to acknowledge some occasional outbreaks of shortages in some limited areas during this period. Large-scale, widespread and longterm supply crises have been recorded mostly in the 19th and early 20th centuries. This coincides with the period of increased presence and pressure of the foreigners in China, who appeared mainly in the coastal region (mostly Westerners, and, to a lesser extent Russians and Japanese traders). Piek argues that early external (i.e., Western) influences were not conducive to technological development because Chinese society did not provide the institutional or legal security needed for foreign investment (p. 30). Given the nature of Western economic operations in China at the time[2] - the terms "foreign investment" for "local technological development," as used by Piek, seem out of place. Instead, it would be more appropriate to use the terms "foreign plunder and exploitation," "local plight and misery" and "local institutional disarray" in case of the 19th century China.

Vastness and distance also prevented the sustained communication and idea fermentation that are essential for the innovation of products, processes and institutions. Piek refers to Needham's explaination (Needham 1970: 82), which attributes the problem of innovation to the absence of an organized and well-assured class of merchants in China, and to the refusal by the Chinese cultural élites and official establishment to accept the "Legalist" school of thought.[3] Piek does not venture further to examine possible reasons for the failure of a merchant class to develop as a solid social force, nor does she try to account for Legalism's limited acceptance as a social philosophy. It would be appropriate to draw linkages, as Piek does not, between these problems and the characteristic features of the Chinese habitat; the vastness of rural agro-pastoral surface and the stronghold of traditional culture could never favour the rise of mercantilism and legalism at the expense of feudalism and supernaturalism.

Sound historical studies have confirmed that merchants were present and quite active in the 
Reviews

Chinese countryside (Elvin 1973). But they were not influential enough to determine the policymaking and legal frameworks that could favour and protect mercantilism. They never did gain the respectability to become social role-model in the traditional Chinese culture. Often they have been depicted as parasites in the popular imagination (e.g., Volti 1982). Even today an average Chinese youngster aims not to be a successful merchant, but a high administrative or military personnel, mostly due to the prestige associated with such positions.

Piek does not adequately attend to the crucial role of Chinese traditional culture in preventing mercantilism and, as a consequence, in the preparation for an earlier industrialization. In the traditional (and quite popular) Chinese view, a person's ideal state of being would be described as a state of wide-heartedness and inner calm that make one feel in total harmony with the fellow human beings, with the community of living and sentient beings and, eventually, with the entire universe (in Chinese, Wu-wei). Role-models like Lao Tzu, Confucius, the Enlightened One (Buddha) and the compassionate beings (Bodhisattva) are believed to have reached that state. Enterpreneurship and industrious behaviour are very distant from the Wu-wei ideal.

In contemporary (i.e., modernized) China, the concept of Wu-wei has continued under a different guise. It is the comfortable and no-worry state guaranteed by the wealth and by a strong, protective network of kinship and firendship. In the traditional view, 'wealth' in the strict material sense was something inferior, not worthy of being discussed loudly, nor to be pursued wholeheartedly. The contemporary Chinese do pursue the material wealth, but silently. They tend to put a lot of ceremonial talks around the money matters even in a serious international business negotiation. Even in today's urban China, open talk about wealth is considered frivolous.

The foundations for today's ongoing industrialization of the Chinese rural interior were laid during the early decades of the People's Republic of China. The communist China drew the attention of the whole world for its radical (and forceful) rural collectivization in the first three decades after the Communist Party's victory (in 1949) under Mao Zhe-dong's revolutionary leadership. Land reform and creation of collective farms were pursued vigorously to raise the rural living standards. At the same time, the price for staple, cotton and other agricultural outputs were kept artificially low to extract a profit that could be used as the source of capital for industrialization. The countryside was organized into large collective enterprises (or communes, comprising two thousand households on average) incorporating the people of several villages. China's agriculture-related rural industries began with the communes.

The rural industrial policies of the $1950 \mathrm{~s}$ and " $60 \mathrm{~s}$ were inspired by a long-term strategy to expose the tradition-bound villagers to industrial workplace and practices and to "proletarianize" them (Starr, 1997), to bring the factories close to their source of supply and, eventually, to the ultimate consumers of their products (i.e., the villagers), to absorb the substantial surplus manpower of the rural economy, to raise the rural life standards, to narrow the urban-rural divide and, most important of all, to enhance self-reliance (autarchy) and national defense by making each region of the country self-sufficient and capable of hosting the national command and launching war efforts in case of occupation or destruction of any other part. Self-reliance and national defense were major obsessions of the Communist Party of China in the first three decades of the People's Republic. Piek's analysis is silent on this policy background of rural collective enterprises and industrialization of the Chinese countryside.

The first steps in the "revolutionary" industrialization (during the "Great Leap Forward") were marked by the creation of steel furnaces (to increase national steel output), mechanical workshops and small manufacturing and processing factories. The steel produced in the rural furnaces turned to be useless for any practical industrial purpose. In the 1970s more factories were opened in the countryside to make China's more than 2,000 counties as self-sufficient as possible in agricultural inputs, construction materials and simple consumer goods. Some of the relatively large and strategically important factories were owned and run by the central government. Some others were owned and managed by the county governments and many others belonged to the communes and townships/village institutions. By the mid-1970s, just before Deng Xiao-ping's 


\section{Reviews}

"open door policy" and reforms, the rural industries were producing about $10 \%$ of China's total industrial output In agricultural inputs (e.g. chemical fertilizers) and construction items (e.g. cement) the small and medium-sized vilage-based industries were producing more than half of the total national output (Starr, 1997).

The rural industries constituted the productive middle-ground, or the second line, of Chinese economic system between the first line of central government-managed and urban-based large industries in the coastal region [4] and the third line of chosen industries established, owned and manged by the People's Liberation Army (PLA) in the remote areas (Gansu, Ningxia, Tibet, Inner Mongolia, Heilogjiang) and elsewhere. Naturally, development of the rural industries was facilitated by the development of the forward base (urban-based, centrally managed large industries) and of the remote area-based PLA's industries. For it bridged the two bases, interacting in diverse ways and gaining technological information from both. The impact of these multiple linkages of early "cellular" village industrial economy (with urban base, PLA and the rural economy), in particular for Sichuan province, is likely to be more illuminating for understanding the roots and trajectory of rural industrialization than only exploring the dual linkage between rural base and urban industries.

New industrial enterprises were launched under the direct ownership and management of village and township governments (i.e., the collectives). Support and encouragement for such enterprises was to be found in the positive results of the farm ownership policy reforms (the wellknown "household responsibility system"), and amplified by the development of transportation and communication infrastructure. During the 1980s and early 1990s there has been steady growth in the rural-based industries, many of which have become integral part of much larger industrial networks of manufacturing, processing, assemblage and supply chains involving other urbanbased and even foreign-based industrial enterprises. Currently, the rural area-based enterprises count for nearly one-fourth of the total industrial production of China providing off-farm jobs to more than 100 million people (SSB/PRC, 1999, Starr, 1997).

Harnessing and developing the technology for rural industries

In China, as elsewhere in the centrally commanded economies, the state has been the major supplier of technology to the rural industries. Before Deng's reforms, rural industries had an important social role as the bridge between the state, which developed technology through its urban-based facilities (science and technology education/reseach facilities and large-scale industries), and the rural masses. The rural industries were to become the disseminator of scientific and technological information in the rural areas. Technological development within the rural industries was also encouraged, and it depended on local institutions such as County Government's Science and Technological Commisssion, Township and Village Enterprise Bureau and local supply cooperatives. To some extent, the mass mobilization campaign of the first three decades of Communist Party rule helped the development of rudimental, practical technology in the rural enterprises (Conroy 1980; Sigurdson 1980). The early radical collectivization of farms was supposed to create medium/large enterprises that could make farm mechanization easier and the development of agri-based industrial technology swifter. State enterprises were supposed to be the major suppliers of new machines and equipment to the rural enterprises through Farm Machinery Stations dislocated in the rural areas. And the stations were supposed to be the points of local technological development and dissemination.

But as the later reports reveal, both functions (supply and development) were far below the expectations and propaganda (ISNAR, 1992). As Piek noted in Sichuan, despite some progress made after the liberalization and reform in the 1980s, the technological level in Chinese countryside remains very limited, as in most of the Third World.

Establishment of rural industries was largely induced by government policies. So was the market-oriented approach introduced later. Despite the responsibility programmes, liberalization and other economic reforms, China is still an essentially command economy. However, with the past two decades of reform, the choice of particular sectors or products, and the merger of small enterprises within a given sector may not be necessarily induced by the government policies. As 
Reviews

Piek mentions in concluding her chapter on establishing and financing technology (p.134), a variety of motivations are possibile - specialized skills, experience and knowledge built up locally, and the local availability of special resources and competencies. Questions remain, however, concerning how the locally available resources and competencies are pooled to develop a particular product or process, and how a convergence is achieved between internal (enterprise) and institutional (local and central government) decision-making? Since the state remains such an important player in this unfolding drama, its articulation with the private sector is an appropriate focus for ongoing analysis.

In underlining the importance of the inter-personal skills and relations as an important factor in harnessing and developing technology, Piek finds that the strategies used to obtain technological information look "rather like industrial espionage," in which the use of personal connections and relations (the well-known guanxi) is of paramount importance. The personal connections, competencies and skills of an ownership and management team play a crucial role in technological development. In unleashing the creativity and guanxi skills of industry leaders, the size and ownership of the enterprise plays a special role. At one end of the scale, the smaller enterprise, locally owned, is well-positioned to activate and enthuse skillful individuals within the firm in acquisition of technology from outside the enterprises. At the same time, the small, locally owned firm is structurally and finacially handicapped to harness and/or to develop technology (a point that Piek clearly illustrates). On the whole, I agree with Piek in pointing that formal qualifications (education) are less important than one's former occupation, experiences and skills. In China, personal skills and connections are often extremely important for favourable relations with higher echelons of power and for market outreach as well as for a suitable interpretation of policies.

Though limited in scope, Piek's case study provides a wealth of interesting data and information about economic and technological aspects of China's rural industries. It is a pity that habitat and cultural traditions that constitute the enduring context of economic and technological developments receive so little attention. Treatment of relevant historical background and current issues in economic policy- and decision-making process at national level is also limited. Piek's work attends carefully, perhaps too carefully, to details of industrialization and technological development concepts, while stinting on an examination of the local and regional cultural forces that have reshaped the natural landscape and can reasonably be expected to play an active role in shaping rural industrial development.

\section{References Cited and Further Reading:}

Elvin, M.,

1973. The Patterns of the Chinese Past, Palo Alto: Stanford University Press.

Findley, C., Watson, A. and Wu, H.X. (eds.).

1994. Rural Enterprises in China. New York: St. Martin's Press.

International Service for National Agricultural Research.

1992. International Seminar on Agricultural Research Management, Summary of Papers, The Hague.

Conroy, R.

1980. "The Growth and Development of the Instruments Sector in China and India: A Comparison," In E. Baark and J. Sigurdson (eds.), India-China Comparative Research. Technology and Science for Development, Studies on Asian Topics No. 3, Scandinavian Institute of Asian Studies, Guildford: Curzon Press.

Ishikawa, S.

1975. The Chinese Method of Technological Development. The Case of the Agricultural

Journal of Political Ecology

Vol. 61999 
Reviews

Machinery and Implement Industry. Developing Economies 13:14-32.

Needham, J.

1970. Clerks and Craftsmen in China and the West, Cambridge: Cambidge University Press.

Piek, H.,

1998. Technology Development in Rural Industries. London/Amsterdam: Intermediate Technology/Thela.

Putterman, L.

1993 Continuity and Change in China's Rural Development: The Collective and Reform

Eras in Perspective, New York/Oxford: Oxford University Press.

Sigurdson, J.

1980. Technology and Science in the PRC. An Introduction, Oxford: Pergamon Press.

Starr,J.B.

1998. Understanding China. London: Profile Books.

State Statistical Bureau of the People's Republic of China.

1999. Statistical Yearbook 1998, Beijing : China Statistical Publishing House.

SSB/PRC,

1998. Statistical Yearbook 1997, Beijing: China Statistical Publishing House. Qi, J.C.

1989. State and Peasant in Contemporary China : The political Economy of Village Government, Berkeley: University of California Press.

Volti, R.

1982. Technology, Politics and Society in China, Boulder: Westview Press.

Yunxiang, Y.

1996. The Flow of Gifts:Reciprocity and Social Networks in a Chinese Village. Palo

Alto: Stanford University Press.

[1] The rural areas of Santai and Qianwei in Sichuan, one of the more populated provinces and a true representative of the Chinese interior, are the field (case/area) of a detailed empirical study by Hannah Piek (Technology Development in Rural Industries: A Study of China's Collectives, London/Amsterdam: Intermediate Technology Publications/Thela Publishers, 1998, $273 \mathrm{pp}$.). The interior comprises the provinces of Anhui, Henan, Hubei, Hunan, Jiangxi, Shaanxi, Shanxi and Sichuan. This interior area is characterized by a relatively mild topography (plains, hills and low mountains) intersected by river basins. The vast majority of the people who inhabit these provinces are of Han ethnicity. They are engaged in primary sector (agro-pastoral) and related trade, light industries and services.

[2] These activities consisted of induction of opium and other illicit trafficking, carving out "spheres of influence" through armed mercenaries to impose unfair treaties and unfavourable (to the Chinese) trade, speculation and expropriation of the Chinese properties, and so forth.

[3] Legalism holds, essentially, that judgments should be meted out according to a code fixed beforehand so as to establish the absolute criteria of correct and incorrect, precluding undue interferences and influences. To some extent, in some of its forms, this orientation is considered 
Reviews

the percursor of modern authoritarianist thinking in China. Legalism is an interesting philosophical stream in the Chinese tradition, but it never gained a wide acceptance either from the elites or the masses. Early forms of Legalism are attributed to the ancient Chinese philosphers, namely Shang Yang, Shen Pu-hai and Shen Tao (all 4th Century BC), Han Fei Tzu and Li Xu (3rd Century BC).

[4] China's coastal regions, most urbanized and densely populated, have absorbed the largest share in direct foreign investment and Chinese government's attention in infrastructures, facilities and services. This has aggravated the already existing regional imbalance amongst the coastal, interior and remote areas. The 13 top-ranking provinces in terms of international investment, economic output and per capita income, are all along China's eastern and southern coastline (cf. SSB/PRC, 1999; Starr, 1998).China's total coastline is almost 32,000 km, of which $18,000 \mathrm{~km}$ is made up by the mainland shore. China claims sovereignty over some 5,400 islands off its coast $(3,870,000 \mathrm{sq} . \mathrm{km}$. of surface and $14,000 \mathrm{~km}$ of island shore). Socially and economically, these islands can be viewed as part of China's coastal region.

\section{Deep Environmental Politics: The Role of Radical Environmentalism in Crafting Environmental Policy, by Phillip F. Cramer, Westport, CT: Praeger Books (1998). xvi, 238 pp.}

\section{Reviewed by Gregory V. Button, School of Public Health, University of Michigan.}

Editor's note: Professor Button is a former journalist and Congressional Fellow who teaches courses on environmental policy and media coverage of environmental issues at the University of Michigan at Ann Arbor.

As the author notes in his preface, few books have been published to date that measure the influence of the Deep Ecology philosophy on the environmental movement, especially its influence on environmental policy. Unfortunately, by the time one has finished reading this book the temptation may be to conclude that the reason for this deficiency is the lack of influence deep ecology has had on the formulation of policy.

The book is divided into three parts. Part One provides the reader with an introduction to the Deep Ecology perspective. Cramer's overview is adequate, if uninspiring. He sketches for the uninformed reader the basic tenets of the philosophical tradition that inspired the Deep Ecology movement and provides a cursory overview of the fundamental canons of the movement. Thus, he sketches for the reader Deep Ecology's rejection of an anthropocentric environmentalism and its major paradigm shift to an environmentalism that is predicated on "ecocentrism" that attempts to create major changes in our perceptions, values and lifestyles. Stressing a harmony with nature and the intrinsic worth of all species, Cramer describes a philosophy that rejects the excessive 